\title{
Adaptive Lumpectomy Boost Planning Can Reduce Normal Tissue Exposure in Patients Receiving Hypofractionated Whole Breast Irradiation
}

\author{
MUTLAY SAYAN ${ }^{1}$, ZEINAB ABOU YEHIA ${ }^{2}$, IMRAAN JAN ${ }^{2}$, APAR GUPTA ${ }^{3}$, IRINA VERGALASOVA ${ }^{2}$, \\ MARC REVIELLO ${ }^{2}$, SHICHA KUMAR ${ }^{4}$, BRUCE HAFFTY ${ }^{2}$ and NISHA OHRI ${ }^{2}$ \\ ${ }^{1}$ Department of Radiation Oncology, Dana-Farber Cancer Institute and Brigham and Women's Hospital, \\ Harvard Medical School, Boston, MA, U.S.A.; \\ ${ }^{2}$ Department of Radiation Oncology, Rutgers Cancer Institute of New Jersey, \\ Rutgers University, New Brunswick, NJ, U.S.A.; \\ ${ }^{3}$ Department of Radiation Oncology, Columbia University Herbert Irving \\ Comprehensive Cancer Center, New York, NY, U.S.A.; \\ ${ }^{4}$ Department of Surgery, Rutgers Cancer Institute of New Jersey, \\ Rutgers University, New Brunswick, NJ, U.S.A.
}

\begin{abstract}
Background/Aim: To evaluate the change in lumpectomy cavity (LPC) volume during hypofractionated radiation (Hypo-RT) and assess the dosimetric benefits of adaptive boost planning on normal tissue exposure in breast cancer patients. Patients and Methods: Two separate computed tomography $(C T)$ simulation scans were obtained. The first (CT1) was used to plan whole breast irradiation, and the second (CT2) was used to plan LPC boost. LPC boost treatment planning was performed on both CT1 and CT2. Results: Mean $L P C$ volume was significantly smaller on CT2 compared to CT1. LPC boost plan comparison showed significant reductions from CT1 to CT2 in mean heart dose and mean lung dose. Mean volume of tissue receiving $95 \%$ of the prescribed boost dose (V95) was lower on CT2 ( $p=0.001)$, as was V80 ( $p<0.001)$ and V50 $(p<0.001)$. Conclusion: LPC volume can change significantly during Hypo-RT. Adaptive LPC boost planning can be considered to reduce normal tissue exposure.
\end{abstract}

This article is freely accessible online.

Part of the study's results has appeared in a poster published in International Journal of Radiation Oncology, Biology, Physics, volume 105, issue 1, supplement E59, 2019.

Correspondence to: Mutlay Sayan, MD, Department of Radiation Oncology, Dana-Farber Cancer Institute, Brigham and Women's Hospital, Harvard University, 75 Francis Street, ASB1 - L2, Boston, MA 02115, U.S.A. Tel: +1 7816245700, e-mail: msayan@ bwh.harvard.edu

Key Words: Breast, carcinoma, hypofractionation, mastectomy, segmental, radiotherapy.
Adjuvant radiation therapy (RT) is a well-established standard of care after breast-conserving surgery (BCS). Conventionally fractionated radiotherapy (Conv-RT) consists of delivering 1.82.0 Gray (Gy) daily per fraction over 5-7 weeks and was previously considered the standard regimen for all breast cancer patients receiving adjuvant RT. Recently updated guidelines endorsed the use of a hypofractionated approach (Hypo-RT) for the majority of women receiving whole breast irradiation (WBI), which entails delivery of $>2.0$ Gy daily per fraction over 3-4 weeks (1). Additional boost irradiation to the lumpectomy cavity (LPC) has been shown to further reduce the risk of ipsilateral breast tumor recurrence and is often delivered following WBI (2-4). However, LPC boost was not consistently delivered in the large randomized studies that established Hypo-RT as a new standard of care (5-8). Therefore, there is a lack of data on the optimal integration of a LPC boost into a Hypo-RT regimen.

Accurate delineation of the LPC is of critical importance, as approximately $75 \%$ of local recurrences occur within the borders of the boost field (9). The LPC is commonly delineated on computed tomography simulation (CT sim) for RT planning. The placement of surgical clips or a BioZorb ${ }^{\circledR}$ marker, the presence of a seroma, breast tissue changes on CT sim, and clinical information on tumor location can aid in LPC delineation. Prior studies have observed significant LPC volume changes during Conv-RT and recommended that re-simulation for boost planning can be considered to ensure appropriate coverage and limit normal tissue exposure (10-12). Despite the widespread adoption of Hypo-RT as a new standard of care, there is limited data on its effect on LPC volume. In this study, we evaluate the change in LPC volume during Hypo-RT and assess the dosimetric benefits of adaptive boost planning on normal tissue exposure. 


\section{Patients and Methods}

We performed a retrospective review of our Institutional database to identify patients treated with Hypo-RT followed by a LPC boost from July 2017 to January 2020 and the requirement for informed patient consent for the use of data was waived (IRB: Pro20170001227). Patients were eligible for this study if they had breast-conserving surgery for invasive cancer or ductal carcinoma in situ (DCIS) and underwent a separate CT sim for LPC boost planning purposes. Patients who received adjuvant chemotherapy after surgery and prior to RT were excluded. Patients who were treated in the prone position for whole breast irradiation and supine position for LPC boost were also excluded.

The standard procedure for CT sim was conducted. Patients were placed on a supine breast board with both arms raised above the head. A custom headrest was made. Additional custom immobilization for the body was not routinely utilized. CT simulation was obtained in two separate sessions: the first CT (CT1) was performed 1-2 weeks before the start of whole breast Hypo-RT, and the second CT (CT2) was performed before the completion of whole breast Hypo-RT, typically during the second or third week of treatment. Organs at risk (OARs) and target volumes were contoured on both CT1 and CT2. The LPC was contoured by the same physician on CT1 and CT2. In an effort to decrease bias, the physician did not refer to the LPC created on CT1 while contouring CT2. Contouring of the LPC was guided by the presence of surgical clips and/or BioZorb ${ }^{\circledR}$ marker, presence of a seroma, post-surgical breast tissue changes, and clinical information on tumor location. Boost treatment planning was carried out on both CT1 and CT2, and dose-volume-histograms (DVHs) were compared. All plans were created by an experienced team of dosimetrists using 9-15 $\mathrm{MeV}$ electrons (n:13) or 6-10 MV photon beams (n:24). CT planning and volumetric calculations were performed using Eclipse version 11 (Varian Medical Systems, Palo Alto, CA, USA).

Adjuvant Hypo-RT was delivered using 3-dimensional conformal radiotherapy (3D-CRT) to the entire breast without regional nodal irradiation. CT-based treatment planning with tangential fields was used for all patients. All patients received 42.56 Gy in 2.66 Gy fractions using 6-15 MV photons, followed by a boost of $10 \mathrm{~Gy}$ to the LPC as delineated on CT2. The heart was excluded from the primary beam using multi-leaf collimator (MLC) blocking. Deep inspiratory breath hold (DIBH) was utilized to limit cardiac exposure when clinically indicated.

Statistical analyses were performed using SPSS statistical software version 25 (IBM Corp., Armonk, NY, USA). Multiple variables were examined for correlation with LPC volume change using the Pearson and Spearman correlation coefficients. Univariate analysis was performed to determine possible associations between LPC volume changes and several clinical and pathologic factors. For the purposes of this analysis, a significant change in LPC volume was defined as a $>20 \%$ LPC volume reduction from CT1 to CT2.

\section{Results}

We identified 37 patients who met the study inclusion criteria. Baseline patient characteristics are shown in Table I. The median age was 54 years (range $=38-85$ years). Mean body mass index (BMI) was $28.7 \mathrm{~kg} / \mathrm{m}^{2}(\mathrm{SD}=5.4)$ and breast volume was $880.6 \mathrm{~cm}^{3}(\mathrm{SD}=379.0)$. Mean tumor size was $11.6 \mathrm{~mm}(\mathrm{SD}=7.6 \mathrm{~mm})$, and the majority $(95 \%)$ of patients were node-negative. Eleven patients $(29.7 \%)$ required breast re-excision. Twenty-six patients $(70.2 \%)$ had a BioZorb ${ }^{\circledR}$ marker placed in the LPC. Patients had no seroma. Median time from last surgery to CT1 was 33 days (range $=22-68$ ). Median time from CT1 to CT2 was 26 days (range=19-37). Comparison of the LPC volume and OARs between CT1 and CT2 are shown in Table II. Mean LPC volume was significantly smaller on CT2 $\left(25.4 \mathrm{~cm}^{3}, \mathrm{SD}=13.2 \mathrm{~cm}^{3}\right)$ compared to CT1 $\left(37.3 \mathrm{~cm}^{3}, \mathrm{SD}=32.0 \mathrm{~cm}^{3}\right)(p<0.001)$. Mean reduction in LPC volume between $\mathrm{CT} 1$ and $\mathrm{CT} 2$ was $18.8 \%$ ( $\mathrm{SD}=27.1 \%)$. LPC boost DVH comparison showed significant reductions from CT1 to CT2 in mean heart dose (7.7 cGy, SD=7.2 cGy vs. 5.4 $\mathrm{cGy}, \mathrm{SD}=3.9 \mathrm{cGy} ; p<0.011)$ and mean lung dose (48.9 cGy, $\mathrm{SD}=39.2 \mathrm{cGy} v s .40 .8 \mathrm{cGy}, \mathrm{SD}=37.6 \mathrm{cGy} ; p<0.001)$ in all patients. Mean heard dose was significantly lower on CT2 in patients with left-sided disease ( $10.4 \mathrm{cGy}, \mathrm{SD}=8.19 \mathrm{cGy} v s .6 .4$ $c G y, \mathrm{SD}=3.19 \mathrm{cGy} ; p<0.001)$. Mean volume of tissue receiving $95 \%$ of the prescribed boost dose (V95) was significantly lower on CT2 $\left(168.1 \mathrm{~cm}^{3}, \mathrm{SD}=91.0 \mathrm{~cm}^{3}\right.$ vs. $142.3 \mathrm{~cm}^{3}, \mathrm{SD}=62.9 \mathrm{~cm}^{3}$; $p=0.001$ ), as was V80 and V50. V105 was similar in both CT1 and CT2 plans $\left(15.1 \mathrm{~cm}^{3}, \mathrm{SD}=22.0 \mathrm{~cm}^{3} v s .13 .5 \mathrm{~cm}^{3}, \mathrm{SD}=20.4\right.$ $\left.\mathrm{cm}^{3} ; p=0.467\right)$.

Comparing the 18 patients (47.4\%) who had a significant ( $>20 \%$ ) reduction in LPC volume to those who did not, there were no significant differences in age, body mass index, breast volume, tumor size, history of re-excision, presence of a BioZorb ${ }^{\circledR}$ marker, time from surgery to CT1, or time from CT1 to CT2 (Table III). Initial LPC volume on CT1 showed a strong correlation with change in LPC volume from CT1 to CT2 (Pearson correlation $\mathrm{r}=0.93, p<0.001$ ) (Table IV).

\section{Discussion}

Within a cohort of breast cancer patients treated with HypoRT followed by LPC boost, we noted that LPC volume changed significantly during Hypo-RT. Analysis of baseline clinical and tumor variables demonstrated that initial LPC volume is strongly correlated with change in LPC volume. Accurate delineation of the LPC is a critical step for boost irradiation. Modern-day CT imaging with additional guidance from surgical clips or a BioZorb ${ }^{\circledR}$ marker can improve LPC delineation. However, the standard in many clinics has been to delineate the LPC using the initial CT sim performed for WBI planning. Prior studies have demonstrated that the LPC volume decreases during the course of Conv-RT (10-14). Oh et al. evaluated the changes in LPC volume after whole-breast Conv-RT and reported a $22.5 \%$ decrease in LPC volume between CT1 and CT2, with a mean decrease of $7 \mathrm{~cm}^{3}$ (13). Flannery et al. reported that in 44 breast cancer patients treated with whole-breast ConvRT, LPC volume decreased $32 \%$ between CT1 and CT2 (median, $11.2 \mathrm{~cm}^{3}$ decrease) (10). Jacobson et al. also 
Table I. Baseline patient characteristics.

\begin{tabular}{lc}
\hline Patients, $\mathrm{n}$ & 37 \\
Age & \\
Median, years (range) & $54(38-85)$ \\
Breast laterality, $\mathrm{n}(\%)$ & $17(46)$ \\
Left & $20(54)$ \\
Right & \\
BMI & $28.7(5.4)$ \\
Mean, $\mathrm{kg} / \mathrm{m}^{2}$ (SD) & \\
Breast volume & $880.6(379.0)$ \\
Mean, $\mathrm{cm}^{3}$ (SD) & \\
Tumor size & $11.6(7.6)$ \\
Mean, mm (SD) & \\
BioZorb ${ }^{\circledR}$ placed & $26(70)$ \\
Yes & \\
AJCC pathologic T stage, $\mathrm{n}(\%)$ & $19(51)$ \\
Tis & $14(38)$ \\
T1 & $4(11)$ \\
T2 & \\
AJCC pathologic N stage, $\mathrm{n}(\%)$ & $35(95)$ \\
N0 & $2(5)$ \\
N1 & \\
Time gap (days), median, range & $33(22-68)$ \\
Surgery to CT1 & $26(19-37)$ \\
CT1 to CT2 & \\
\hline
\end{tabular}

SD: Standard deviation; BMI: body mass index.

Table II. Comparison of the LPC volume and organs at risk between CT1 and CT2.

\begin{tabular}{|c|c|c|c|}
\hline & CT1 & $\mathrm{CT} 2$ & $p$-Value \\
\hline \multicolumn{4}{|l|}{ LPC Volume } \\
\hline Mean, $\mathrm{cm}^{3}(\mathrm{SD})$ & $37.3(32.0)$ & $25.4(13.2)$ & 0.005 \\
\hline \multicolumn{4}{|l|}{ Heart dose (cGy) } \\
\hline Mean, $\mathrm{cm}^{3}(\mathrm{SD})$ & $7.7(7.2)$ & $5.4(3.9)$ & $<0.001$ \\
\hline \multicolumn{4}{|l|}{ Heart dose (cGy)* } \\
\hline Mean, $\mathrm{cm}^{3}(\mathrm{SD})$ & $10.4(8.2)$ & $6.4(3.2)$ & $<0.001$ \\
\hline \multicolumn{4}{|c|}{ Ipsilateral lung dose (cGy) } \\
\hline Mean, $\mathrm{cm}^{3}(\mathrm{SD})$ & $48.9(39.2)$ & $40.8(37.6)$ & $<0.001$ \\
\hline \multicolumn{4}{|l|}{ V105 } \\
\hline Mean, $\mathrm{cm}^{3}(\mathrm{SD})$ & $15.1(22.0)$ & $13.5(20.4)$ & 0.467 \\
\hline \multicolumn{4}{|l|}{ V95 } \\
\hline Mean, $\mathrm{cm}^{3}(\mathrm{SD})$ & $168.1(91.0)$ & $142.3(62.6)$ & $<0.001$ \\
\hline \multicolumn{4}{|l|}{ V80 } \\
\hline Mean, $\mathrm{cm}^{3}(\mathrm{SD})$ & $236.2(112.1)$ & $203.0(80.8)$ & $<0.001$ \\
\hline \multicolumn{4}{|l|}{ V50 } \\
\hline Mean, $\mathrm{cm}^{3}(\mathrm{SD})$ & $347.5(133.6)$ & $304.6(105.1)$ & $<0.001$ \\
\hline
\end{tabular}

LPC: Lumpectomy cavity; SD: standard deviation; Vx: the mean volume receiving X Gy. *Patients with left-sided disease.

analyzed the change in LPC volume in breast cancer patients after whole-breast Conv-RT and found a $>20 \%$ decrease in LPC volume between CT1 and CT2 done 4 to 5 weeks apart (mean, $16.1 \mathrm{~cm}^{3}$ decrease) (14).
Table III. Comparison of baseline characteristics between patients with and without significant $(>20 \%)$ reduction in LPC volume.

\begin{tabular}{lccc}
\hline & $<20 \%$ Change & $>20 \%$ Change & $p$-Value \\
\hline $\begin{array}{l}\text { Patient, } \mathrm{n} \\
\text { Age }\end{array}$ & 18 & 19 & \\
$\quad$ Median, years (SD) & $54.6(6.9)$ & $57.2(13.1)$ & 0.464 \\
$\quad$ BMI & & & \\
$\quad$ Mean, kg/m ${ }^{2}$ (SD) & $28.0(6.0)$ & $29.4(4.8)$ & 0.451 \\
Breast volume & & & \\
$\quad$ Mean, $\mathrm{cm}^{3}$ (SD) & $794.8(423.4)$ & $971.2(312.1)$ & 0.160 \\
Tumor size & & & \\
$\quad$ Mean, mm (SD) & $11.7(8.5)$ & $11.5(6.9)$ & 0.943 \\
$\quad \begin{array}{l}\text { Re-excision (\%) } \\
\text { BioZorb }{ }^{\circledR} \text { marker (\%) }\end{array}$ & $4(21)$ & $7(39)$ & 0.235 \\
$\quad$ Surgery to CT1 & $12(63)$ & $14(79)$ & 0.331 \\
$\quad$ Mean, days (SD) & $36(11)$ & $37(12)$ & 0.848 \\
CT1 to CT2 (days) & & $27(5)$ & 0.196 \\
$\quad$ Mean, days (SD) & $25(4)$ & $27(5)$ \\
\hline
\end{tabular}

LPC: Lumpectomy cavity; SD: standard deviation; BMI: body mass index.

Table IV. Correlation of LPC volume decrease with clinical variables.

\begin{tabular}{lrc}
\hline & $\mathrm{r}^{*}$ & $p$-Value \\
\hline Age & 0.23 & 0.167 \\
BMI & -0.06 & 0.745 \\
Breast volume & 0.29 & 0.087 \\
Initial LPC volume & 0.93 & $<0.001$ \\
Surgery to CT1 (days) & -0.20 & 0.237 \\
CT1 to CT2 (days) & 0.12 & 0.469 \\
\hline
\end{tabular}

LPC: Lumpectomy cavity; BMI: body mass index. *Pearson and Spearman correlation coefficients.

Hypo-RT is now the standard of care for the majority of women receiving WBI per consensus guidelines (1). This is followed by a LPC boost in many cases. Therefore, it is important to assess the change in LPC volume during the course of Hypo-RT. Similar to prior studies with Conv-RT, our results demonstrated that the LPC volume decreases significantly during the course of Hypo-RT (mean CT1 37.3 $\mathrm{cm}^{3}$ vs. CT2 $25.4 \mathrm{~cm}^{3}, p=0.005$ ). Furthermore, adaptive LPC boost planning can significantly reduce normal tissue exposure, including cardiac exposure. It has been well documented that the risk of radiation-related long-term cardiotoxicity increases linearly in a dose-dependent fashion without apparent threshold (15). Similarly, ipsilateral mean lung and ipsilateral lung V20 are the most important parameters in predicting pulmonary toxicity (16).

Our analysis also suggests that a select group of patients may benefit most from adaptive LPC boost planning. We showed a significant correlation between the initial LPC 
volume and the decrease in volume between CT1 and CT2. Flannery et al. similarly reported that there is a significant correlation between initial LPC volume and decrease in volume during the course of Conv-RT ( $p=0.001)(10)$. Therefore, it may not be necessary to routinely perform adaptive LPC boost planning during Hypo-RT. Instead, this can be considered for patients with large initial LPC volume. Furthermore, omission of RT is an option in selected patients (17-19).

Limitations of our study include its small sample size, retrospective design, and inherent confounding factors that cannot be completely accounted for in a non-randomized study. These limitations may have affected the result of this study. In addition, longer follow-up is needed to assess the potential clinical benefits of re-simulation for LPC boost planning.

In conclusion, LPC volume changes significantly during Hypo-RT. Initial LPC volume is significantly correlated with change in LPC volume. Adaptive LPC boost planning can reduce normal tissue exposure. Longer follow-up is needed to assess the clinical benefits of re-simulation for LPC boost planning in the setting of Hypo-RT.

\section{Conflicts of Interest}

The Authors declare no conflicts of interest.

\section{Authors' Contributions}

MS, BH, and NO designed the study. MS, ZAY, IJ, AG, IV, and MR collected the data. MS, and IV performed the data analysis. MS, and NO drafted the manuscript. ZAY, AG, IJ, SK, and BH edited the article. All Authors approved the final content for journal submission and publication.

\section{References}

1 Smith BD, Bellon JR, Blitzblau R, Freedman G, Haffty B, Hahn C, Halberg F, Hoffman K, Horst K, Moran J, Patton C, Perlmutter J, Warren L, Whelan T, Wright JL and Jagsi R: Radiation therapy for the whole breast: Executive summary of an American Society for Radiation Oncology (ASTRO) evidence-based guideline. Pract Radiat Oncol 8(3): 145-152, 2018. PMID: 29545124. DOI: 10.1016/j.prro.2018.01.012

2 Bartelink H, Horiot JC, Poortmans PM, Struikmans H, Van den Bogaert W, Fourquet A, Jager JJ, Hoogenraad WJ, Oei SB, Wárlám-Rodenhuis CC, Pierart M and Collette L: Impact of a higher radiation dose on local control and survival in breastconserving therapy of early breast cancer: 10 -year results of the randomized boost versus no boost EORTC 22881-10882 trial. J Clin Oncol 25(22): 3259-3265, 2007. PMID: 17577015. DOI: 10.1200/JCO.2007.11.4991

3 Bartelink H, Maingon P, Poortmans P, Weltens C, Fourquet A, Jager J, Schinagl D, Oei B, Rodenhuis C, Horiot JC, Struikmans $\mathrm{H}$, Van Limbergen E, Kirova Y, Elkhuizen P, Bongartz R, Miralbell R, Morgan D, Dubois JB, Remouchamps V, Mirimanoff RO, Collette S, Collette L and European Organisation for Research and Treatment of Cancer Radiation
Oncology and Breast Cancer Groups: Whole-breast irradiation with or without a boost for patients treated with breastconserving surgery for early breast cancer: 20-year follow-up of a randomised phase 3 trial. Lancet Oncol 16(1): 47-56, 2015. PMID: 25500422. DOI: 10.1016/S1470-2045(14)71156-8

4 Romestaing P, Lehingue Y, Carrie C, Coquard R, Montbarbon X, Ardiet JM, Mamelle N and Gérard JP: Role of a 10-Gy boost in the conservative treatment of early breast cancer: results of a randomized clinical trial in Lyon, France. J Clin Oncol 15(3): 963968, 1997. PMID: 9060534. DOI: 10.1200/JCO.1997.15.3.963

5 START Trialists' Group, Bentzen SM, Agrawal RK, Aird EG, Barrett JM, Barrett-Lee PJ, Bentzen SM, Bliss JM, Brown J, Dewar JA, Dobbs HJ, Haviland JS, Hoskin PJ, Hopwood P, Lawton PA, Magee BJ, Mills J, Morgan DA, Owen JR, Simmons S, Sumo G, Sydenham MA, Venables K and Yarnold JR: The UK Standardisation of Breast Radiotherapy (START) Trial B of radiotherapy hypofractionation for treatment of early breast cancer: a randomised trial. Lancet 371(9618): 1098-1107, 2008. PMID: 18355913. DOI: 10.1016/S0140-6736(08)60348-7

6 Haviland JS, Owen JR, Dewar JA, Agrawal RK, Barrett J, Barrett-Lee PJ, Dobbs HJ, Hopwood P, Lawton PA, Magee BJ, Mills J, Simmons S, Sydenham MA, Venables K, Bliss JM, Yarnold JR and START Trialists' Group: The UK Standardisation of Breast Radiotherapy (START) trials of radiotherapy hypofractionation for treatment of early breast cancer: 10-year follow-up results of two randomised controlled trials. Lancet Oncol 14(11): 1086-1094, 2013. PMID: 24055415. DOI: $10.1016 / \mathrm{S} 1470-2045(13) 70386-3$

7 Owen JR, Ashton A, Bliss JM, Homewood J, Harper C, Hanson J, Haviland J, Bentzen SM and Yarnold JR: Effect of radiotherapy fraction size on tumour control in patients with early-stage breast cancer after local tumour excision: long-term results of a randomised trial. Lancet Oncol 7(6): 467-471, 2006. PMID: 16750496. DOI: 10.1016/S1470-2045(06)70699-4

8 Whelan TJ, Pignol JP, Levine MN, Julian JA, MacKenzie R, Parpia S, Shelley W, Grimard L, Bowen J, Lukka H, Perera F, Fyles A, Schneider K, Gulavita S and Freeman C: Long-term results of hypofractionated radiation therapy for breast cancer. N Engl J Med 362(6): 513-520, 2010. PMID: 20147717. DOI: 10.1056/NEJMoa0906260

9 Gage I, Recht A, Gelman R, Nixon AJ, Silver B, Bornstein BA and Harris JR: Long-term outcome following breast-conserving surgery and radiation therapy. Int J Radiat Oncol Biol Phys 33(2): 245-251, 1995. PMID: 7673011. DOI: 10.1016/03603016(95)02001-R

10 Flannery TW, Nichols EM, Cheston SB, Marter KJ, Naqvi SA, Markham KM, Ali I and Mohiuddin MM: Repeat computed tomography simulation to assess lumpectomy cavity volume during whole-breast irradiation. Int J Radiat Oncol Biol Phys 75(3): 751756, 2009. PMID: 19289260. DOI: 10.1016/j.jirobp.2008.11.024

$11 \mathrm{Cho} \mathrm{H}$ and Kim C: Volumetric changes in the lumpectomy cavity during whole breast irradiation after breast conserving surgery. Radiat Oncol J 29(4): 277-282, 2011. PMID: 22984681. DOI: $10.3857 /$ roj.2011.29.4.277

12 Chung MJ, Suh YJ, Lee HC, Kang DG, Kim EJ, Kim SH and Lee JH: Tumor bed volumetric changes during breast irradiation for the patients with breast cancer. Radiat Oncol J 31(4): 228233, 2013. PMID: 24501711. DOI: 10.3857/roj.2013.31.4.228

13 Oh KS, Kong FM, Griffith KA, Yanke B and Pierce LJ: Planning the breast tumor bed boost: changes in the excision 
cavity volume and surgical scar location after breast-conserving surgery and whole-breast irradiation. Int J Radiat Oncol Biol Phys 66(3): 680-686, 2006. PMID: 16863683. DOI: 10.1016/j.ijrobp.2006.04.042

14 Jacobson G, Betts V and Smith B: Change in volume of lumpectomy cavity during external-beam irradiation of the intact breast. Int J Radiat Oncol Biol Phys 65(4): 1161-1164, 2006. PMID: 16682143. DOI: 10.1016/j.ijrobp.2006.02.009

15 Darby SC, Ewertz M, McGale P, Bennet AM, Blom-Goldman U, Brønnum D, Correa C, Cutter D, Gagliardi G, Gigante B, Jensen MB, Nisbet A, Peto R, Rahimi K, Taylor C and Hall P: Risk of ischemic heart disease in women after radiotherapy for breast cancer. N Eng1 J Med 368(11): 987-998, 2013. PMID: 23484825. DOI: 10.1056/NEJMoa1209825

16 Meattini I, Guenzi M, Fozza A, Vidali C, Rovea P, Meacci F and Livi L: Overview on cardiac, pulmonary and cutaneous toxicity in patients treated with adjuvant radiotherapy for breast cancer. Breast Cancer 24(1): 52-62, 2017. PMID: 27025498. DOI: 10.1007/s12282-016-0694-3

17 Kunkler IH, Williams LJ, Jack WJ, Cameron DA, Dixon JM and PRIME II investigators: Breast-conserving surgery with or without irradiation in women aged 65 years or older with early breast cancer (PRIME II): a randomised controlled trial. Lancet Oncol 16(3): 266-273, 2015. PMID: 25637340. DOI: $10.1016 /$ S1470-2045(14)71221-5
18 Hughes KS, Schnaper LA, Berry D, Cirrincione C, McCormick B, Shank B, Wheeler J, Champion LA, Smith TJ, Smith BL, Shapiro C, Muss HB, Winer E, Hudis C, Wood W, Sugarbaker D, Henderson IC, Norton L, Cancer and Leukemia Group B, Radiation Therapy Oncology Group and Eastern Cooperative Oncology Group: Lumpectomy plus tamoxifen with or without irradiation in women 70 years of age or older with early breast cancer. N Engl J Med 351(10): 971-977, 2004. PMID: 15342805. DOI: $10.1056 /$ NEJMoa040587

19 Ishitobi M, Fukui R, Hashimoto Y, Kittaka N, Nakayama T and Tamaki Y: Safety for repeat lumpectomy without radiotherapy for ipsilateral breast tumor recurrence. Anticancer Res 37(9): 52935299, 2017. PMID: 28870967. DOI: 10.21873/anticanres.11955

Received September 18, 2021

Revised October 8, 2021

Accepted November 1, 2021 